\title{
Fallacies and fantasies: the theoretical underpinnings of the Coexistence Approach for palaeoclimate reconstruction
}

\author{
Guido W. Grimm ${ }^{1}$ and Alastair J. Potts ${ }^{2}$ \\ ${ }^{1}$ University of Vienna, Department of Palaeontology, Vienna, Austria \\ ${ }^{2}$ Nelson Mandela Metropolitan University, Centre of Coastal Palaeoscience, Port Elizabeth, South Africa \\ Correspondence to: Guido W. Grimm (guido.grimm@univie.ac.at)
}

Received: 18 November 2015 - Published in Clim. Past Discuss.: 18 December 2015

Revised: 25 February 2016 - Accepted: 29 February 2016 - Published: 10 March 2016

\begin{abstract}
The Coexistence Approach has been used to infer palaeoclimates for many Eurasian fossil plant assemblages. However, the theory that underpins the method has never been examined in detail. Here we discuss acknowledged and implicit assumptions and assess the statistical nature and pseudo-logic of the method. We also compare the Coexistence Approach theory with the active field of species distribution modelling. We argue that the assumptions will inevitably be violated to some degree and that the method lacks any substantive means to identify or quantify these violations. The absence of a statistical framework makes the method highly vulnerable to the vagaries of statistical outliers and exotic elements. In addition, we find numerous logical inconsistencies, such as how climate shifts are quantified (the use of a "centre value" of a coexistence interval) and the ability to reconstruct "extinct" climates from modern plant distributions. Given the problems that have surfaced in species distribution modelling, accurate and precise quantitative reconstructions of palaeoclimates (or even climate shifts) using the nearest-living-relative principle and rectilinear niches (the basis of the method) will not be possible. The Coexistence Approach can be summarised as an exercise that shoehorns a plant fossil assemblage into coexistence and then assumes that this must be the climate. Given the theoretical issues and methodological issues highlighted elsewhere, we suggest that the method be discontinued and that all past reconstructions be disregarded and revisited using less fallacious methods. We outline six steps for (further) validation of available and future taxon-based methods and advocate developing (semi-quantitative) methods that prioritise robustness over precision.
\end{abstract}

\section{Introduction}

One of the most widely used methods to infer the palaeoclimates of Eurasia using fossil plant assemblages is the "Coexistence Approach" (Utescher et al., 2014). Conceptually, this approach belongs to the family of mutual climate range techniques but also makes use of the "nearest-living-relative" principle; a nearest living relative (NLR) is a modern taxon (species, group of species, genus or higher) that is considered an analogue for the fossil taxon. Such mutual climate range methods use the climatic preferences of modern species (a set of nearest living relatives), as defined by their current distribution, to infer the potential climatic niche for a fossil assemblage. In the case of the Coexistence Approach, the climate niche is defined using minimum and maximum climate values of an NLR, obtained from its present-day distribution. Pure mutual climate range techniques are usually restricted to reconstructing palaeoclimates of the recent past (i.e. Quaternary) where species in the fossil assemblages can be directly linked to modern species (e.g. Elias, 1997, 2001; Thompson et al., 2012; Harbert and Nixon, 2015); the processes of extinction and speciation are ignored and niche conservatism is considered to be the norm. However, to apply these palaeoclimate reconstruction techniques to assemblages from older time periods requires the use of the nearest-living-relative principle, which is linked to the concept of physiological uniformitarianism (Tiffney and Manchester, 2001; Tiffney, 2008). The niche space of an NLR is used to represent that of the fossil taxon. Thus, one assumes that the climate niche of the NLR (the modern species or species set) is identical to that of the associated fossil taxon (an extinct sister or ancestral species) and the mutually shared climate range of 


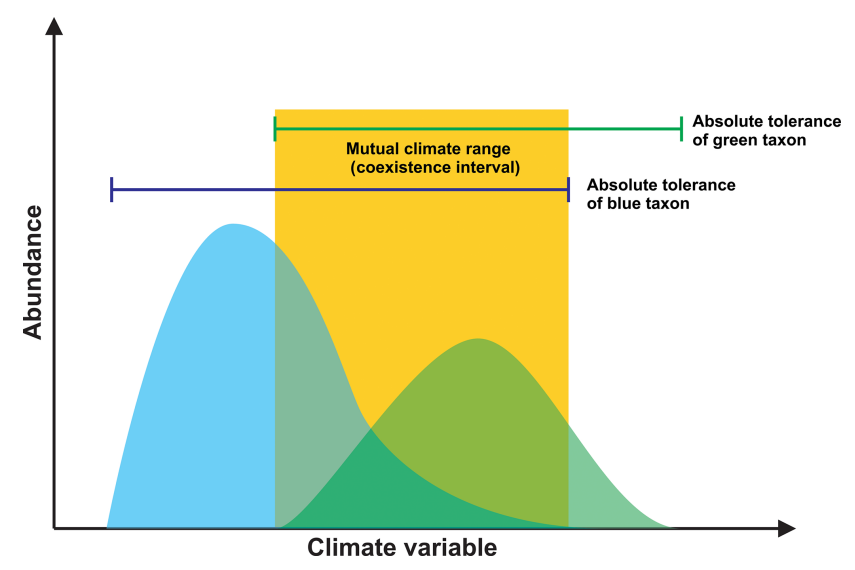

Figure 1. The concept of the mutual climate range as used in the Coexistence Approach.

the NLRs enables the estimation of the climate conditions in which the fossil assemblage thrived (Fig. 1).

Despite the availability of alternative palaeoclimate reconstruction techniques using NLRs and the mutual climate range approach (e.g. Greenwood et al., 2005), the Coexistence Approach has become the de facto method for plant fossil assemblages of Eurasia for time periods spanning the Miocene to Late Cretaceous (Utescher et al., 2014). The cumulative citation count of studies using the Coexistence Approach is in excess of 10000 . On the surface, it reconstructs precise palaeoclimatic conditions (usually reported with a precision of $0.1^{\circ} \mathrm{C}$ and $1 \mathrm{~mm}$ precipitation per month or year) based on a series of acknowledged and implicit basic assumptions (Table 1; Mosbrugger and Utescher, 1997; Utescher et al., 2014). These assumptions appear straightforward but have theoretical and practical implications not addressed in the application of the Coexistence Approach (Mosbrugger and Utescher, 1997; Utescher et al., 2014; Grimm et al., 2015). Furthermore, the Coexistence Approach avoids any statistical processing (Mosbrugger and Utescher, 1997; Utescher et al., 2014) and, hence, does not take into account most community information, which could help to identify errors and exotic elements. We argue that it relies to some degree on illogical deductions, some of which are advocated as strengths of the method, e.g. the ability to reconstruct "extinct" climates (Utescher et al., 2014). The applicability of the nearest-living-relative principle for reconstructing past climates in a quantitative manner has never been questioned. This is surprising in the light of ongoing discussions in the field of spatial distribution modelling, which shares a number of assumptions with mutual climate range and nearest-living-relatives methods. Below we discuss each of these issues in further detail.

\section{Theoretical background of the Coexistence Approach}

\subsection{Assumptions of the Coexistence Approach}

Mosbrugger and Utescher (1997) list four basic assumptions that need to be fulfilled (Table 1). The first assumption has never been used in the application of the Coexistence Approach, and the three others superimpose additional uncertainty on the method and are easily violated, particularly if the aim is high accuracy and precision. Notably, none of the assumptions have been tested and verified for taxa commonly used in the Coexistence Approach.

The first assumption is anchored in the ability to define a "systematically close" NLR (Table 1). However, Mosbrugger and Utescher (1997) or Utescher et al. (2014) do not provide a framework on how to quantify systematically close and in what respect systematic closeness should be relevant for the identification of the NLR. A focus on systematic closeness can lead to conflict with the nearest-living-relative principle. This principle is based on overall morphological similarity and not necessarily linked to phylogenetic relatedness, which is the current basis of systematics. Thus, a fossil may be systematically close to a modern species (or group) that has undergone significant shifts in morphology and fundamental niche, and the best modern analogue may be a more distantly related lineage that has been morphologically and ecologically stable (Fig. 2a). In addition, the degree of systematic relatedness of a fossil to an NLR requires the placement of fossils within a phylogenetic framework (i.e. a tree or network) and this has never been explored in any Coexistence Approach study.

There are further issues with Assumption 1 when considering the taxonomic affiliation of an NLR. Given the time span separating ancient assemblages and modern-day taxa, it has been agreed that defining an NLR at the species level is highly problematic (Grimm and Denk, 2012; Utescher et al., 2014). Thus, the Coexistence Approach usually defines an NLR as the genus or family to which the fossil can be assigned, with rare instances of an intrageneric lineage or a modern species (Grimm and Denk, 2012; Utescher et al., 2014; Grimm et al., 2015). For example, the NLR of a fossil oak leaf would be genus Quercus, the NLR of a deciduous, convexly lobed oak leaf would be Quercus Group Quercus (the white oak clade) and the NLRs of a fagaceous fossil of unknown generic affinity would be all Fagaceae. Hence, systematically close, as used in the Coexistence Approach and other nearest-living-relative approaches, translates into simply being a member of the same taxonomic rank (e.g. genus or family), and the actual phylogenetic (i.e. systematic) distances between fossils and their NLRs are never established. Under this implementation, assignment of NLRs to higher taxonomic ranks (above species) includes the taxonomic problems linked to paraphyly (exclusive common origin; Fig. 2b). Fossils of a paraphyletic group will have differ- 
Table 1. The assumptions of the Coexistence Approach (quotations from Utescher et al., 2014).

\begin{tabular}{|c|c|}
\hline Description & Issues \\
\hline $\begin{array}{l}\text { Assumption 1: "For fossil taxa systematically closely } \\
\text { related nearest living relatives (NLRs) can be identi- } \\
\text { fied." }\end{array}$ & $\begin{array}{l}\text { (a) Lack of a theoretical framework to define a system- } \\
\text { atically close relative. } \\
\text { (b) Concept of physiological uniformitarianism as- } \\
\text { sumes a common origin but does not need quantifica- } \\
\text { tion of phylogenetic closeness. }\end{array}$ \\
\hline $\begin{array}{l}\text { Assumption 2: "The climatic requirements of a fossil } \\
\text { taxon are similar to those of its nearest living rela- } \\
\text { tive." }\end{array}$ & $\begin{array}{l}\text { (a) Physiological uniformitarianism cannot be gener- } \\
\text { ally assumed. } \\
\text { (b) Different taxonomic ranks between fossils and } \\
\text { their nearest living relatives. }\end{array}$ \\
\hline $\begin{array}{l}\text { Assumption 3: "The climatic requirements or tol- } \\
\text { erances of a nearest living relative [i.e. minimum } \\
\text { and maximum tolerances regarding single parame- } \\
\text { ters that are considered per se to be independent of } \\
\text { each other] can be derived from its [current] area of } \\
\text { distribution". }\end{array}$ & $\begin{array}{l}\text { (a) Distribution is not necessarily a function of climate } \\
\text { but also other biotic and abiotic parameters: the re- } \\
\text { alised niche < fundamental niche. } \\
\text { (b) Minimum and maximum tolerances are poor esti- } \\
\text { mates for the climatic niche of a taxon. } \\
\text { (c) Climate parameters are not independent of each } \\
\text { other. } \\
\text { (d) There are no working frameworks to test whether a } \\
\text { potential nearest living relative fulfils Assumption } 3 \text {. }\end{array}$ \\
\hline $\begin{array}{l}\text { Assumption 4: "The modern climatic data used are } \\
\text { reliable and of good quality". }\end{array}$ & $\begin{array}{l}\text { More or less violated in all studies that applied the Co- } \\
\text { existence Approach (see Grimm and Denk, 2012) }\end{array}$ \\
\hline $\begin{array}{l}\text { Assumption 5: Palaeo-assemblages represent actual } \\
\text { communities. }\end{array}$ & $\begin{array}{l}\text { (a) Fossils may be allochthonous, in particular micro- } \\
\text { fossils (pollen). } \\
\text { (b) Fossils may not be strictly coeval (macrofossil } \\
\text { lagerstätten usually cover substantial time periods). }\end{array}$ \\
\hline $\begin{array}{l}\text { Assumption 6: Absence of a fossil in a palaeo- } \\
\text { assemblage is evidence of true absence. }\end{array}$ & The fossil record is incomplete. \\
\hline
\end{tabular}

ent systematic distances to the modern members of the specified taxonomic group of NLRs. However, this is not a problem for the combination of mutual climate range approaches and nearest-living-relative principle as long as the assumption of physiological uniformitarianism is fulfilled (Assumption 2). Thus, shared ancestry remains important, but the systematic closeness of Assumption 1 is superfluous for the application of mutual climate range techniques making use of the nearest-living-relative concept.

The second assumption (Table 1) is based upon the concept of physiological uniformitarianism (Tiffney and Manchester, 2001; Tiffney, 2008). Physiological uniformitarianism implies that as long as lineage stays within its environmental niche, it will not accumulate morphological changes. Hence, a modern species with the same, or very similar, morphological traits of a fossil of the same evolutionary lineage should share the same environmental niche. It also implies that members of the lineages that have undergone niche shifts also experienced morphological changes. Assumption 2 is likely to be violated when morphological changes are evident between the fossil and modern members of an evolutionary lineage, and an NLR of a fossil specimen should only be used if there is morphological, not mere taxonomic, similarity and if both have a common origin. This would exclude the use of most modern plant genera and all families as NLRs as they are typically composed of morphologically divergent species.

In addition, the use of morphologically diverse taxonomic groups to represent an NLR usually means that the environmental niche of the NLR is large, likely encompassing the niche of the fossil, but is not "climatically similar" to that of the fossil, thus, directly violating Assumption 2. Novel procedures and methods are required that take cognisance of the fact that the NLR niche is likely to be far broader than can be expected for that of the fossil. The actual assumption, as used by the Coexistence Approach and related mutual climate range methods, is that the climatic niche of a fossil taxon lies somewhere within the range of niches found within the species comprising the NLR. This has two major implications for the set-up and interpretation of reconstructed palaeoclimates using the Coexistence Approach (and other mutual climate range techniques that use NLRs): (1) a highresolution climate reconstruction should not be possible, especially when only minimum and maximum NLR tolerances 

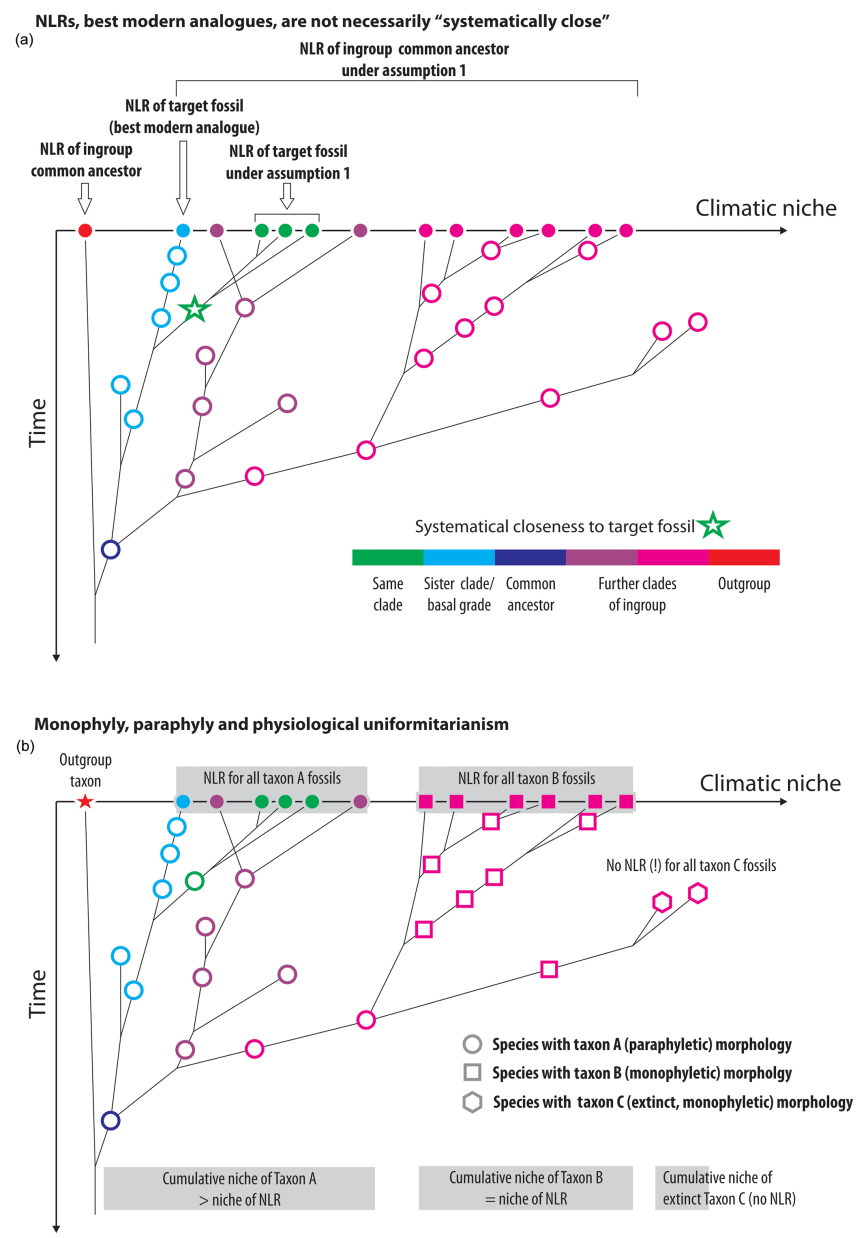

Figure 2. Difference between systematically close and nearest living relative (NLR, i.e. best modern analogues). Shown is a species phylogeny of a diversified ingroup; the outgroup in this example is a sister species of the ingroup. Panel (a): standard definition of nearest living relative (best modern analogue) vs. definition if Assumption 1 of the Coexistence Approach should be fulfilled. Panel (b): same tree as in (a), only that each species is categorised as a member of a distinct morphotaxon that can be distinguished in the fossil record. Note that all morphotaxa are mutually exclusive regarding their climatic niche, but there is no strict correlation between systematic closeness (phylogeny) and the climatic niche of the fossils and their nearest living relatives (modern species of the same morphotypes as the fossils).

are used (Fig. 3a), and (2) mixed floras may not be identified since mutually exclusive species (or communities) have overlapping climate ranges at higher taxonomic levels (Fig. 3b). Thus, highly precise and accurate climate reconstructions can only be obtained using the Coexistence Approach if the critical species within a palaeo-assemblage occupied niches close to the minimum and maximum tolerances of their corresponding modern genus or family level NLRs.
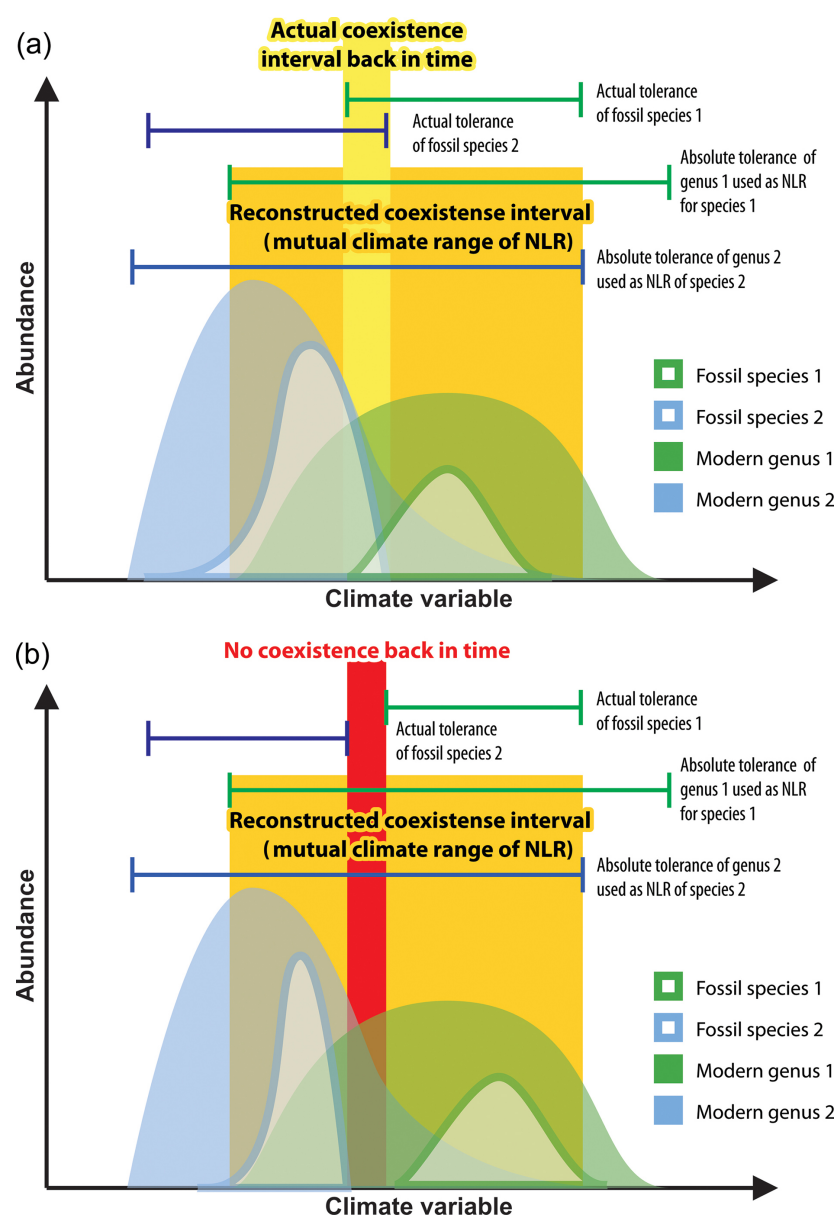

Figure 3. Issues related to the use of higher-level taxonomic classification (e.g. genus or family) as nearest living relatives (NLRs) of fossil species. In this example, two fossil species occupy a climate range within the modern climate range of their selected genus-level NLRs, fulfilling the principle of physiological uniformitarianism. Panel (a): the fossil species have a narrow shared climate range and coexisted in the past. The use of higher-level taxonomic ranks as NLRs will lead, in most cases, to a much broader and less precise reconstructed coexistence interval. Panel (b): the fossil species are mutually exclusive, but the expansion of the niche space - due to the use of genera as NLRs - results in a coexistence interval (i.e. pseudo-coexistence).

The third assumption (Table 1), that the distributions of extant species are in equilibrium with their climate, is a topic rich in discussions in the ecological and species distribution modelling literature (Araújo and Pearson, 2005; Bond et al., 2005; Sexton et al., 2009; Franklin, 2010). Species are often not in equilibrium with their climate for abiotic (e.g. soil, fire) or biotic (e.g. competition) reasons, and thus their realised niches do not span their fundamental niches. Thus, species will be plastic in their expression of the realised niche depending on external factors, which would exclude the reconstruction of palaeoclimate with high accuracy. Any change in the abiotic or biotic parameters can affect the dis- 
tribution of a species (i.e. its realised niche) even if the fundamental niche remains unchanged.

The climatic niche is solely represented by minimum and maximum values in the Coexistence Approach, which are independently compiled for climate parameters in a univariate manner. However, it has been long established that biological climate niches are multidimensional (Köppen, 1936; Hutchinson, 1957; Walter, 1973; Walter and Breckle, 19831991; Schroeder, 1998). Using minimum-maximum tolerances along univariate axes can only roughly approximate the multidimensional climatic niche and may be misleading (Klotz, 1999; Thompson et al., 2012). For example, two mutually exclusive taxa, for which Assumption 3 applies, may still have an artificial mutual climate range regarding their minimum and maximum tolerances (Fig. 4a). In this context it is important to note that species distribution modelling started with algorithms that used minimum and maximum values but quickly moved on to methods that better represented the bioclimatic niche of a species (discussed further below). Thus, the use of range values for climatic parameters does not accurately capture the climatic requirements or tolerances of an NLR (Table 1), which will affect the reconstructed palaeoclimate using the Coexistence Approach.

The fourth and last assumption has no apparent theoretical implications. Technical implications have been discussed in Grimm and Denk (2012), Thompson et al. (2012), Utescher et al. (2014) and Grimm et al. (2015). We do, however, wish to highlight that since local climate can substantially vary over short timescales, minimum and maximum tolerances may be unduly affected by the selected observation period of climate stations.

Not formally addressed by Mosbrugger and Utescher (1997) or Utescher et al. (2014) are two more fundamental assumptions of the Coexistence Approach, which distinguish the method from mutual climate range techniques using modern-day species: (1) palaeo-assemblages comprise only taxa that existed as actual communities (i.e. all fossil specimens are autochthonous and from the same point in time); (2) absence of a fossil taxon indicates true absence (i.e. each fossil plant assemblage comprehensively reflects the actual palaeo-community; Table 1). The Coexistence Approach implicitly assumes that only an autochthonous and strictly coeval palaeo-assemblage will result in a single coexistence interval. However, given that two mutually exclusive taxa can share a climate range of minimum and maximum along univariate climate parameters, so too can allochthonous taxa in a fossil assemblage. In addition, the expansion of the climate niche using higher-level NLRs automatically increases the probability of artificial coexistence. Thus, allochthonous assemblages (mixed floras) do not necessarily result in "ambiguous" intervals (Fig. 4b-d; e.g. Utescher et al., 2014) and may very well be the reason for highly precise palaeoclimate estimates $\left(<1{ }^{\circ} \mathrm{C}\right.$ for temperature parameters; $<100 \mathrm{~mm}$ precipitation per year; $<10 \mathrm{~mm}$ precipitation per month) observed in many studies using the Coexistence Ap-
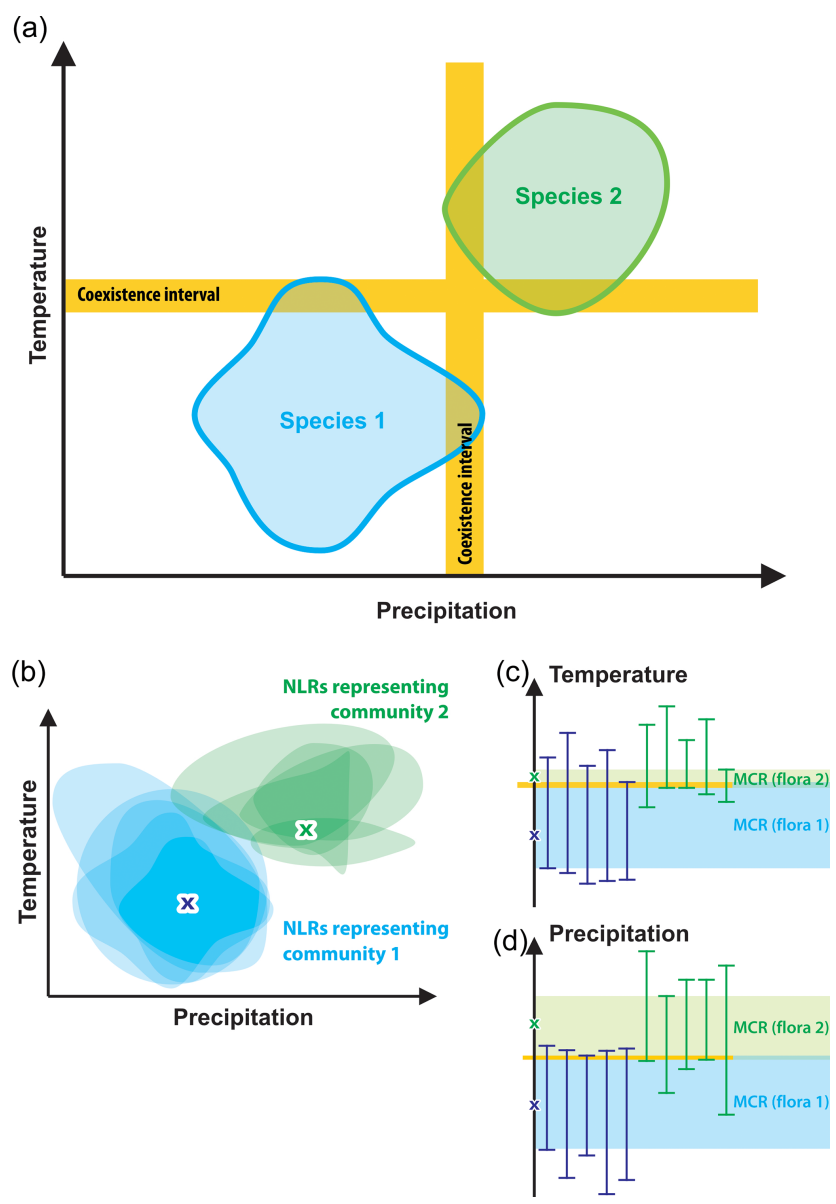

Figure 4. Pseudo-coexistence as a result of the representation of the climate niche using minimum and maximum tolerances. Panel (a): bivariate climate niches of two mutually exclusive species. These species have no overlapping climate space but still reconstruct narrow coexistence intervals (orange bars) along univariate axes. Panel (b): bivariate climate niches of NLRs of two floras growing under substantially different climates (indicated by $\mathrm{x}$ ). Note that only the niches of three of the Community 1 species overlap with one or two of the Community 2 species. Panels (c, d): univariate mutual climate ranges (MCR) of both communities; the overlap of the two MCR result in highly precise coexistence intervals for the artificially mixed communities including all elements from Community 1 and Community 2.

proach (Denk et al., 2012; Grimm et al., 2015). Thompson et al. (2012) suggest that a benefit of mutual climate range techniques, in comparison to indicator-species approaches, is that the reconstruction is only affected by the presence of taxa, not their absence. However, this does not apply to the Coexistence Approach, where the mere absence of a taxon can directly affect the outcome of the reconstruction (discussed further below). For instance, the absence of a taxon may eliminate another NLR as a "climatic outlier" rather than producing two ambiguous intervals. 
We have outlined a range of probable and inevitable issues of the purported basic assumptions of the Coexistence Approach. These will all, to some unknown degree, decrease the precision and accuracy of any approach that attempts to reconstruct palaeoclimates. In this light, the Coexistence Approach is highly unlikely to reconstruct precise or accurate palaeoclimatic conditions. Utescher et al. (2014) state that it is impossible to test the accuracy of Coexistence Approach reconstructions (but see Grimm and Denk, 2012, for mean annual temperature estimates) but follow the original paper in assuming that violation of the basic assumptions will readily surface in the form of climatic outliers.

\subsection{The statistical nature of the Coexistence Approach}

According to Utescher et al. (2014) the "Coexistence Approach by Mosbrugger and Utescher (1997) is a nearestliving-relative method, which relies only on the presence or absence of a plant taxon within a fossil assemblage and the climatic requirements of its modern relatives. It avoids any statistical processing or further assumptions, except those given in Mosbrugger and Utescher (1997) [i.e. the four basic assumptions, see Table 1]". In the original paper, no means of statistical processing were proposed; hence, the Coexistence Approach defines an interval for a past climate parameter assuming that statistical effects do not exist or are negligible. The Coexistence Approach discounts the majority of the community information because the reconstructed climate interval is always solely defined by the pair of the two most divergent but putatively coexisting NLRs. Usually one member of the pair is an exotic element; here we define exotic as any NLR whose niche is at odds with the majority of the assemblage (e.g. Fig. 5). The likelihood of potential oddities, errors or violations of assumptions increases with assemblage size or depositional age. The Coexistence Approach relies, however, on the presumption that any violation will readily surface in the form of so-called climatic outliers (Mosbrugger and Utescher, 1997; Utescher et al., 2014). This exposes palaeoclimate reconstructions using this approach to the vagaries of statistical outliers and exotic elements (see Grimm and Denk (2012) and Grimm et al. (2015) for realworld data examples).

A climatic outlier is identified as an NLR or small number of NLRs that do not share the climate space of a given parameter with a slightly higher number of other NLRs (Fig. 5). In those cases where there is more than one interval that can be reconstructed using the same maximum possible number of NLRs, then alternative (ambiguous) intervals are reported; each of these intervals recognises a different set of climatic outliers. Ambiguous intervals are interpreted by Utescher et al. (2014) as the only evidence for mixed floras rather than a violation of any of the assumptions discussed above. Taxa identified as climatic outliers are typically removed from a Coexistence Approach analysis for a given palaeoassemblage and parameter. We wish to highlight that a cli-

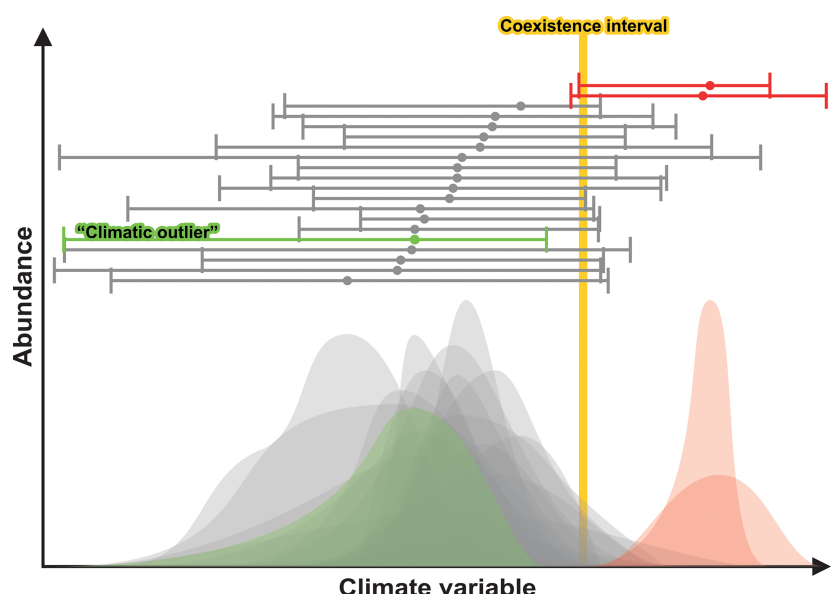

Figure 5. Climatic outliers and the bias of the Coexistence Approach towards exotic nearest living relatives (NLRs). Shown are the niche response curves for 20 potential NLRs, of which 18 (grey and green) show a general overlap in their climatic preference. The two red NLRs are exotic elements with strongly differing climatic preferences. Bars indicate the minimum and maximum tolerances of each NLR; the dots highlight each NLR's optimal climate value. Because the green NLR has no shared climate range with the two exotic NLRs (red), it would be excluded as a climatic outlier following the Coexistence Approach protocol. The resultant coexistence interval (orange bar) is highly precise but reflects neither the climatic preference of the non-exotic (grey and green) nor exotic group of NLRs (red).

matic outlier is simply an NLR that is seemingly at odds with a few other NLRs and must not be confused with a statistical outlier (Fig. 5).

There are two paramount problems with the outlier elimination strategy used by the Coexistence Approach. First, two taxa violating the assumptions behind the Coexistence Approach may eliminate one taxon that is not. A typical situation is illustrated in Fig. 5, where an NLR occupying a climate range that is in general agreement with the rest of the flora would be identified and eliminated as a climatic outlier because of the presence of two deviant taxa that are at odds with the overall NLR community. Second, taxa identified as climatic outliers for one climatic parameter and therefore removed from the assemblage for estimating that parameter are still, in most cases, kept for analysing other parameters for the same assemblage. In some cases, these climatic outliers even define the coexistence interval in another parameter (Grimm et al., 2015). If we follow the logic that climatic outliers represent violations of the basic assumptions of the Coexistence Approach (Utescher et al., 2014), then it is imperative that they are removed from all reconstructions for a given assemblage or in general (Table 2). This has been rarely applied in any study that has identified climatic outliers in the Coexistence Approach, mainly to avoid wide, and thus uninformative, coexistence intervals (Grimm and Denk, 2012; Grimm et al., 2015). It could be argued that any palaeo- 
assemblage represented by mutually exclusive NLRs should be ignored until the reason for the non-coexistence can be identified and corrected for.

Any mutual climate range approach needs a framework to identify statistical outliers as the assumptions will inevitably be violated, and establishing the degree of violation (e.g. degree of niche shifts) is not feasible based on current knowledge. Many palaeo-assemblages will comprise mixed floras with elements from different climate niches, and this would need to be explicitly addressed before reconstructing coexistence intervals. As stated above, the Coexistence Approach lacks any framework to identify exotic elements or allochthonous assemblages, unless they are sufficiently divergent to generate climatic outliers. Allochthonous assemblages comprising mutually exclusive species can share a climate interval (Fig. 4b), and this problem of pseudocoexistence is exacerbated by the use of higher-level taxa (genera, families) as NLRs of a fossil species or morphotypes. Any slightly conflicting, but exotic, element in an assemblage will have a disproportionally high influence on the palaeoclimate estimates (Fig. 5). It is clear that not only climatic outliers and ambiguous intervals should be indicative of mixed floras, errors in the data or violations in the assumptions but also any narrow coexistence interval (see Grimm and Denk, 2012; Grimm et al., 2015, for real-world examples).

Mutual climate range techniques that apply simple statistics to filter exotic taxa, such as the Bioclimatic Approach (Greenwood et al., 2005), will be less susceptible to the presence and absence of a few exotic taxa but will also usually fail to recognise mixed floras. The problem of mixed floras can only be overcome, to some degree, by using alternative mutual climate range techniques that make use of the full spectrum of distributional information and thus include the climatic preference of all constituent elements of a palaeo-assemblage (e.g. by using the niche curves in Fig. 5). This includes methods such as the weighted mutual climate range approach (Thompson et al., 2012), the probability density function method (Chevalier et al., 2014) and the coexistence likelihood estimation method (Harbert and Nixon, 2015). However, these methods will probably begin to break down when the nearest-living-relative principle is needed to link fossils with extant lineages (Thompson et al., 2012; Harbert and Nixon, 2015), and this may explain why their application has been limited to Quaternary assemblages.

\subsection{Logical inconsistencies of the Coexistence Approach}

We wish to highlight four additional points regarding the use of the Coexistence Approach that lack any (bio)logical basis, specifically: (1) the use of the centre value to identify and quantify climatic shifts, (2) that the reconstructed climate is based on only two nominally coexisting elements, (3) that the reconstructed climate is highly dependent on the presence or absence of a single or few taxa, and (4) the reconstruction of extinct climates. We elaborate on each of these points below.

The conclusions of most Coexistence Approach studies rely on shifts observed in the so-called centre value. This value is simply the arithmetic mean of the upper and lower boundary of the coexistence interval. Practical tests have shown that there is little correlation between the actual climate and the centre value (Klotz, 1999; Grimm and Denk, 2012). The use of this value highlights a fundamental misunderstanding of the niche concept. If we imagine the coexistence interval to be correct, then all values within the interval should be equally probable as no other information is incorporated regarding the probabilities of occurrence of the assemblage. Selecting the centre value as an indicator of a shift in climate makes no statistical or biological sense. For example, Fig. 6a shows two plant assemblages that differ only by the climatic preference of a single NLR. The replacement of one NLR by another with a preference towards lower values gives rise to a reconstructed climate shift towards higher values using the centre value.

Many Coexistence Approach reconstructions rely on the presence of NLRs that nominally coexist, even if these elements have climate tolerances that are at odds with the rest of the assemblage (Fig. 5; cf. Grimm and Denk, 2012; Grimm et al., 2015). In extreme cases the same coexistence interval can be reconstructed based on plant assemblages with contrary climate tolerances (Fig. 6b). In Fig. 6b, the elements of two plant assemblages have contrary climate tolerances and it is the two exotic taxa in each assemblage that ensure that the reconstructed coexistence intervals are the same. Thus, the precision of the reconstructed palaeoclimates is often entirely dependent on the presence or absence of specific, usually exotic NLRs. Across Coexistence Approach studies, a handful of NLRs that occur towards the tolerance margins over the entirety of all palaeo-floras usually determine the coexistence intervals; it is these few NLRs that give rise to the praised precision of the technique (Grimm and Denk, 2012; Grimm et al., 2015).

The presence or absence of individual NLRs is generally at the root of reconstruction uncertainty in coexistence interval - we term this the Heisenberg effect. Figure 6c shows two very similar assemblages where the presence or absence of the two highlighted taxa changes the coexistence interval reconstructed by the Coexistence Approach to a degree that would be interpreted as a trend towards higher values. The Heisenberg effect renders palaeoclimate estimates obtained with the Coexistence Approach protocol highly susceptible to taxon-bias effects. The reconstructed climate is exceedingly dependent on what fraction of the actual vegetation has been captured by the fossil assemblages (note that in Fig. 6c all NLRs have a mutually shared climate range). Thus, even if all assumptions needed for a mutual climate range approach that also uses the nearest-living-relative principle are fulfilled, the Heisenberg effect will lead to unstable, 
Table 2. The consequences of identifying a climatic outlier in a palaeo-assemblage supposing that these represent violations of one or more of the four basic assumptions.

\begin{tabular}{ll}
\hline Violation of basic assumption & Consequence \\
\hline $\begin{array}{l}\text { 1. The nearest living relative (NLR) is not a } \\
\text { close relative of a fossil taxon. }\end{array}$ & $\begin{array}{l}\text { There is no consequence as long as the NLR } \\
\text { shares the same lineage and is a good physio- } \\
\text { logical modern analogue. }\end{array}$ \\
\hline $\begin{array}{l}\text { 2. The climatic requirements of the fossil taxon } \\
\text { are different from that of the NLR. }\end{array}$ & $\begin{array}{l}\text { If different for one climate parameter, the NLR } \\
\text { may be equally non-representative of other cli- } \\
\text { mate parameters of the fossil taxon. Any coex- } \\
\text { istence interval including this fossil taxon may } \\
\text { be misinformed. }\end{array}$ \\
\hline $\begin{array}{l}\text { 3. The NLR's distribution is not representa- } \\
\text { tive of its climatic requirements (relict distri- } \\
\text { bution). }\end{array}$ & $\begin{array}{l}\text { Coexistence intervals delimited by the NLR are } \\
\text { likely to be misinformed in any study using the } \\
\text { NLR. }\end{array}$ \\
\hline $\begin{array}{l}\text { 4. The modern climate data to estimate NLR } \\
\text { minimum and maximum tolerances are unreli- } \\
\text { able. }\end{array}$ & $\begin{array}{l}\text { If this is the case, then no coexistence interval } \\
\text { is reliable and palaeoclimate reconstruction us- } \\
\text { ing modern analogues is impossible. }\end{array}$ \\
\hline
\end{tabular}

even random, climate reconstructions when the Coexistence Approach is used.

Utescher et al. (2014) explicitly state that, as each parameter is independently reconstructed, the Coexistence Approach has the potential to reconstruct a climate that does not exist today: an extinct climate. It is hard to grasp how this can be logically accommodated within the basic assumptions of the Coexistence Approach and the actuo-palaeontological nearest-living-relative principle in general (Fig. 7). An extinct climate for a palaeo-assemblage would indicate that the present-day niches of the NLRs are not representative of the fossils and therefore would indicate direct violations of Assumptions 2 and 3 discussed above (Table 1). In addition, it is not possible to construct an extinct climate using species that are restricted to present-day climates if the principle of physiological uniformitarianism applies. Reasons why extinct climates are reconstructed using the Coexistence Approach include violations of basic assumptions, pseudocoexistence, the inconsistent identification of climatic outliers within an assemblage across climate variables and the single-dimension effect where climate parameters are analysed in isolation and are assumed to be unlinked. The reconstruction of an extinct climate should be seen as a direct indication of error and not lauded as a benefit of the method.

Leaving aside these logical inconsistencies in the conception and application of the method, the Coexistence Approach still cannot be expected to reproduce a robust quantitative reconstruction of the palaeoclimate, as (1) assumptions are likely to be violated but cannot be detected, (2) one cannot avoid using higher-level taxa to represent fossil species or morphotypes, and (3) the fossil record will always be incomplete to different degrees and this will affect the calculated coexistence interval.

\section{Lessons to be learnt from species distribution modelling}

Species distribution modelling (SDM) is an exceptionally active field which aims to empirically model the speciesenvironment relationships and thereby quantify the realised niche of a given taxon (Franklin, 2010; Peterson et al., 2011) or, in some cases, communities (e.g. Potts et al., 2013). The beginnings of the field lie in the BIOCLIM software package (Nix, 1986), which is comparable to the Coexistence Approach as it used the range (or percentile range) of climatic variables in a rectilinear fashion. Booth et al. (2014) describe the origins of the field and highlight that one of the most active areas of SDM development has been in methods that trim the rectilinear climate envelopes of BIOCLIM. The development was driven by the early realisation that the relationships between climate variables were poorly captured by the rectilinear approach; for example, a rectilinear niche may suggest that a species could survive in a situation where it is both hot and dry, but the actual climate niche indicates that it only occurs where it is hot and wet. More advanced methods have refined the $n$-dimensional hyperniche (Hutchinson, 1957) where response curves are used to capture the suitability of different conditions for species occurrence. BIOCLIM performed poorly in comparison to more recent methods in a comparison of more recent SDM methods (Elith et al., 2006), indicating that the simplistic use of range values for climatic variables, as used by the Coexistence Approach, is a poor representation of the realised niche of species or NLR.

The revolution in the multidimensional quantification of the niche has completely bypassed the Coexistence Approach. Measuring ecological niche overlap between species in multivariate space is an active area of investigation (Rödder and Engler, 2011; Broennimann et al., 2012), which can 
(a)

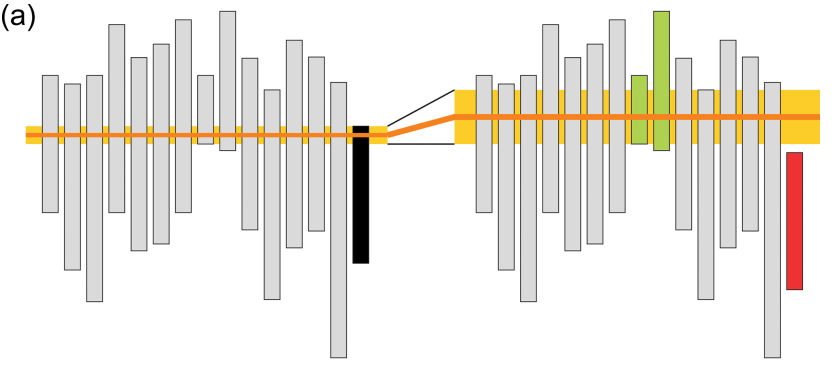

(b)

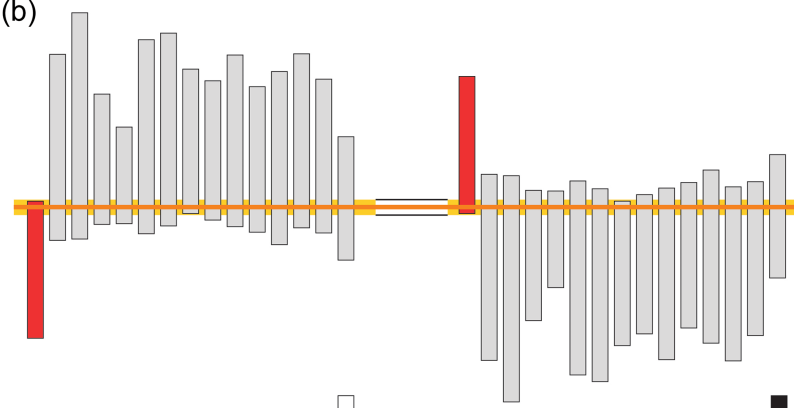

(c)

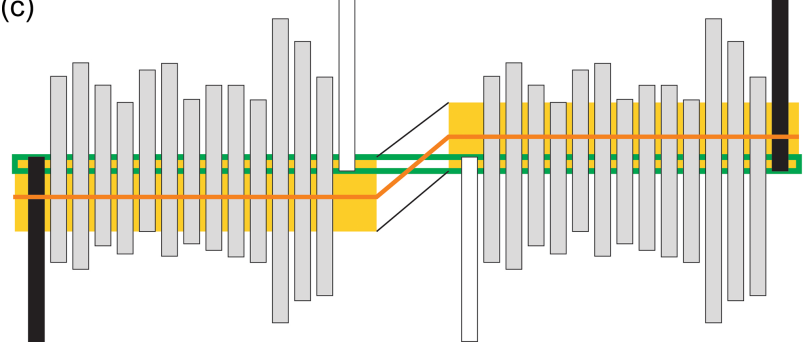

Figure 6. Logical inconsistencies in the application and theory of the Coexistence Approach. Shown are coexistence intervals (orange bars) based on slightly (a, c) or extremely (b) different sets of nearest living relatives (NLRs). Panel (a): use of the centre value to determine climate shifts. A single NLR (black) is replaced by an NLR tolerant to lower values (red), which would be eliminated as a climatic outlier by the two green NLRs, thus leading to a higher centre value. Panel (b): all NLRs have contrasting climate tolerances, the exotic taxa in both floras (red) ensure that the reconstructed coexistence interval is the same. Panel (c): two floras that only differ by the absence (white bars) or presence (black bars) of two taxa. The resulting coexistence intervals would be interpreted as a shift towards higher values. The dark green box shows the coexistence interval of a flora in which both taxa are represented.

be used to determine the shared niche within a set of species. However, measuring the niche in such a manner also requires that all the variables selected are, in fact, significant in limiting the niche. Establishing the contribution and importance of different environmental variables (i.e. variable selection) in setting the bounds of a taxon's niche is a theoretical issue (Araújo and Guisan, 2006) where advances are also being made (Austin and Van Niel, 2011). In comparison, the Coexistence Approach blindly uses a wide range of environmental parameters in a univariate manner assuming that they are all important in determining a taxon's niche.

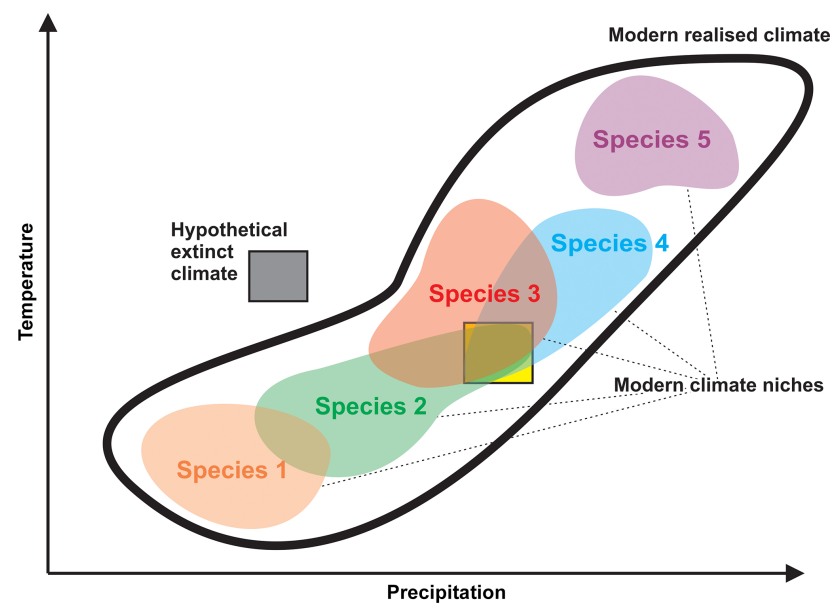

Figure 7. Impossibility of reconstructing extinct climates with the nearest-living-relative (NLR) principle. Shown are the (realised) climate niches of five modern species, which, inevitably have to lie within the frame of the modern climate space. Any coexistence space (yellow square, showing the coexistence space of species 2, 3 and 4 using their minimum and maximum tolerances) must reflect a climate situation also found today. Any extinct climate (grey square) could only be defined by the coexistence of species with climate niches different to those found in modern species, species with no living NLR or species belonging to lineages that underwent niche shift.

Furthermore, the assumption of niche conservatism (linked to the principle of physiological uniformitarianism) has generated considerable debate in the SDM literature as it has been used as justification for projecting models into altered climate states (past or future) and to predict the establishment and spread of invasive species (reviewed in Pearman et al., 2008a). These discussions have centred firstly on whether the current distribution for a given species, i.e. the realised niche, adequately represents the fundamental niche and secondly on how quickly the fundamental niche may be able to shift. Such concerns are absent in the theoretical underpinnings of the Coexistence Approach (Mosbrugger and Utescher, 1997; Utescher et al., 2014). Unfortunately, niche shifts have been documented for a wide range of plant species through space (Broennimann et al., 2007; Pearman et al., 2008a) and even over relatively short timescales (Pearman et al., 2008b; Veloz et al., 2011). Therefore, the assumption of physiological uniformitarianism has limited applicability to reconstruct precise and accurate palaeoclimates, especially with increasing age of an assemblage.

\section{Conclusions}

Using best possible climate data for modern North American woody plants, Thompson et al. (2012) were unable to reconstruct the climatic shifts from the Last Glacial Maximum to the present-day using an unweighted mutual climatic range 
method (which represents the niche using range values and is equivalent to the Coexistence Approach save for the use of NLRs and recognition of climatic outliers). This is in stark contrast to the beliefs of Coexistence Approach practitioners that the method can reliably reconstruct climate shifts at high precision (e.g. Huang et al., 2015; Utescher et al., 2015), despite the additional error and uncertainty associated with the nearest-living-relative principle. The purported high precision in Coexistence Approach studies is dependent on phenomena such as pseudo-coexistence and the lack of a statistical framework.

We argue that the Coexistence Approach, as conceived by Mosbrugger and Utescher (1997), violates the basic concepts behind mutual climate range techniques and the nearestliving-relative principle. It imposes a number of assumptions that will inevitably be violated, has no ability to detect violations and lacks any safeguards against the reconstruction of artificial coexistence intervals and thus erroneous palaeoclimate estimates.

Given the theoretical problems outlined here and the practical problems highlighted by Grimm et al. (2015) - for example, that any random real-world flora will eventually produce a "statistically significant" (according Mosbrugger and Utescher, 1997) coexistence interval with a high number (>20) of NLRs - we suggest that palaeoclimate reconstructions using the Coexistence Approach be disregarded and that the palaeo-assemblages be revisited with other methods and careful, well-documented and well-investigated NLR associations.

\section{Where to go from here?}

There are already a range of potential methods available for palaeoclimate reconstruction using plant fossils as proxies in a univariate manner that have been rarely used or recently proposed (e.g. Greenwood et al., 2005; Boyle et al., 2008; Thompson et al., 2012; Chevalier et al., 2014; Harbert and Nixon, 2015), and there are avenues ripe for exploration (see, e.g., Broennimann et al., 2012; Denk et al., 2013). However, all of these methods require (further) testing and then careful, well-documented usage when reconstructing palaeoclimates. The development of the physiognomic approach (CLAMP, Climate Leaf Analysis Multivariate Program) within the last 2 decades may serve as an example regarding validation, advancement and, most importantly, documentation and transparency. The various publications demonstrate a constant effort to reach higher precision and counter known problems (e.g. Kovach and Spicer, 1995; Herman and Spicer, 1997; Spicer et al., 2009; Yang et al., 2015; Li et al., 2016). All primary data are made freely accessible and means are implemented allowing for quick application (CLAMP online; Yang et al., 2011). CLAMP online not only provides data, guidelines and templates for application but also pinpoints shortcomings and ideas on how to deal with them. No method is or will be perfect. Nevertheless, it is crucial to define the principal accuracy and precision of any quantitative method. If this is not possible, as in the case of the Coexistence Approach (Utescher et al., 2014, p. 61), it must not be used. Therefore, we suggest that any current or future taxon-based method be

1. tested against the modern flora (e.g. Boyle et al., 2008; Thompson et al., 2012; Chevalier et al., 2014; Harbert and Nixon, 2015).

2. tested with randomised and unlikely communities of modern flora. A robust (taxon-based) method that is to be applied to micro-, meso- and macrofossil assemblages must detect possible allochthonous elements or mixed floras.

3. first applied to the better-understood palaeoclimates of the most recent past (e.g. present to the Last Glacial Maximum) and compared with available relevant proxies (e.g. Thompson et al., 2012).

4. explored using both species level and taxonomic levels of potential or probable nearest living relatives (e.g. Boyle et al., 2008).

5. examined using a jackknifing or similar procedure to ensure that results remain accurate and establish the actual precision that can be expected with fossil floras. Fossil floras will always only provide a fraction of the actual flora and may include incorrectly determined taxa. The accuracy of a result must not change due to the presence or absence of specific taxa in the assemblage, although precision can, and is likely to, decline.

6. finally, tested in a stepwise fashion further and further into the past using available, well-studied, dated, and more or less continuous records, such as the recently revised Icelandic record covering the last 15 million years, ranging from subtropical lowland to ice age conditions (Denk et al., 2011, 2013)

After such a series of tests, the method can be considered an alternative means to reconstruct past climates for further exploration. However, the ultimate limitations of mutual climate range techniques or other nearest-living-relative methods for palaeoclimate reconstruction do not lie in the methodological framework to estimate, for example, the coexistence space but rather in the applicability of the nearest-livingrelative principle. When it comes to application in the more distant past, the basic assumption of any method must be that the nearest-living-relative principle will be violated to an unknown degree. The degree of violation will likely increase with time and may not necessarily surface during the application or testing phase. Bivariate or multivariate approaches, which can tackle the problem of pseudo-coexistence (e.g. Fig. 4), will be more sensible in this respect. The capability to accurately and precisely predict palaeoclimate will not 
only deteriorate with increasing age but also with compositional change of the fossil plant assemblages relative to the modern-day situation. Precise, highly sophisticated methods (e.g. Punyasena, 2008; Harbert and Nixon, 2015) or methods using few, overly precise, values to characterise the niche space of the NLR (e.g. Greenwood et al., 2005) run a higher risk of being affected by violations of the nearest-livingrelative principle than methods that use semi-quantitative approximations of the niche (e.g. Thompson et al., 2012; Denk et al., 2013).

Taking into account all theoretical and practical issues involved, we suspect that quantitative palaeoclimate estimates at a high precision and accuracy are an impossible goal when the nearest-living-relative principle is be applied. Therefore, our opinion is that method development should not focus on high (or higher) precision, as the basis of this precision is undermined as the temporal difference between fossil and NLR increases, but rather on establishing climate change trends in a robust and reproducible manner. Semiquantitative approaches can detect such changes and may prove to be more robust (e.g. the Köppen signature approach proposed by Denk et al., 2013). Furthermore, the application of any nearest-living-relative method to palaeo-floras will always depend on the thoughtful filtering of a fossil assemblage for elements that have been shown to have a high likelihood of niche conservatism. Fossil-NLR associations must be carefully selected to ensure that the principle of physiological uniformitarianism applies, in contrast to the current practice of seemingly data-naive bulk analyses.

Acknowledgements. This study was funded by the Austrian Science Fund (FWF) with a grant to Guido W. Grimm, project number M1751-B16. Alastair J. Potts received support from the National Research Foundation (RCA13091944022).

Edited by: J. Guiot

\section{References}

Araújo, M. B. and Guisan, A.: Five (or so) challenges for species distribution modelling, J. Biogeogr., 33, 1677-1688, 2006.

Araújo, M. B. and Pearson, R. G.: Equilibrium of species' distributions with climate, Ecography, 28, 693-695, 2005.

Austin, M. P. and Van Niel, K. P.: Improving species distribution models for climate change studies: variable selection and scale, J. Biogeogr., 38, 1-8, 2011.

Bond, W. J., Woodward, F. I., and Midgley, G. F.: The global distribution of ecosystems in a world without fire, New Phytol., 165, 525-538, 2005.

Booth, T. H., Nix, H. A., Busby, J. R., and Hutchinson, M. F.: BIOCLIM: the first species distribution modelling package, its early applications and relevance to most current MaxEnt studies, Divers. Distr., 20, 1-9, 2014.

Boyle, B., Meyer, H. W., Enquist, B., and Salas, S.: Higher taxa as paleoecological and paleoclimatic indicators: A search for the modern analog of the Florissant fossil flora, Geol. Soc. Am. Sp. Paper, 435, 33-51, 2008.

Broennimann, O., Treier, U. A., Müller-Schärer, H., Thuiller, W., Peterson, A. T., and Guisan, A.: Evidence of climatic niche shift during biological invasion, Ecol. Lett., 10, 701-709, 2007.

Broennimann, O., Fitzpatrick, M. C., Pearman, P. B., Petitpierre, B., Pellissier, L., Yoccoz, N. G., Thuiller, W., Fortin, M.-J., Randin, C., Zimmermann, N. E., Graham, C. H., and Guisan, A.: Measuring ecological niche overlap from occurrence and spatial environmental data, Global Ecol. Biogeogr., 21, 481-497, 2012.

Chevalier, M., Cheddadi, R., and Chase, B. M.: CREST (Climate REconstruction SofTware): a probability density function (PDF)based quantitative climate reconstruction method, Clim. Past, 10, 2081-2098, doi:10.5194/cp-10-2081-2014, 2014.

Denk, T., Grímsson, F., Zetter, R., and Símonarson, L. A.: Late Cainozoic Floras of Iceland: 15 Million Years of Vegetation and Climate History in the Northern North Atlantic, Springer, Heidelberg, New York, 854 pp., 2011.

Denk, T., Grimm, G. W., and Röseler, A.-K.: When field botany meets history: taxonomy of Platanus mexicana in Mexico, Willdenowia, 42, 99-115, 2012.

Denk, T., Grimm, G. W., Grímsson, F., and Zetter, R.: Evidence from "Köppen signatures" of fossil plant assemblages for effective heat transport of Gulf Stream to subarctic North Atlantic during Miocene cooling, Biogeosciences, 10, 7927-7942, doi:10.5194/bg-10-7927-2013, 2013.

Elias, S. A.: Review of Palaeoentomology of the Kap København Formation, a Plio-Pleistocene Sequence in Peary Land, North Greenland by Jens Böcher, Arctic Alpine Res., 29, p. 140, 1997.

Elias, S. A.: Mutual climatic range reconstructions of seasonal temperatures based on Late Pleistocene fossil beetle assemblages in Eastern Beringia, Quaternary Sci. Rev., 20, 77-91, 2001.

Elith, J., Graham, C. H., Anderson, R. P., Dudík, M., Ferrier, S., Guisan, A., Hijmans, R. J., Huettmann, F., Leathwick, J. R., Lehmann, A., Li, J., Lohmann, L. G., Loiselle, B. A., Manion, G., Moritz, C., Nakamura, M., Nakazawa, Y., Overton, J. M., Peterson, A. T., Phillips, S. J., Richardson, K. S., ScachettiPereira, R., Schapire, R. E., Soberón, J., Williams, S., Wisz, M. S., and Zimmermann, N. E.: Novel methods improve prediction of species distributions from occurrence data, Ecography, 29, 129-151, 2006.

Franklin, J.: Mapping Species Distributions: Spatial Inference and Prediction, Cambridge University Press, Cambridge, UK, 2010.

Greenwood, D. R., Archibald, S. B., Mathewes, R. W., and Moss, P. T.: Fossil biotas from the Okanagan Highlands, southern British Columbia and northeastern Washington State: climates and ecosystems across an Eocene landscape, Can. J. Earth Sci., 42, 167-185, 2005.

Grimm, G. W. and Denk, T.: Reliability and resolution of the coexistence approach - A revalidation using modern-day data, Rev. Palaeobot. Palynol., 172, 33-47, 2012.

Grimm, G. W., Bouchal, J. M., Denk, T., and Potts, A. J.: Fables and foibles: a critical analysis of the Palaeoflora database and the Coexistence Approach for palaeoclimate reconstruction, bioRxiv, doi:10.1101/016378, 2015.

Harbert, R. S. and Nixon, K. C.: Climate reconstruction analysis using coexistence likelihood estimation (CRACLE): A method for the estimation of climate using vegetation, Am. J. Bot., 102, 1277-1289, 2015. 
Herman, A. B. and Spicer, R. A.: New quantitative palaeoclimate data for the Late Cretaceous Arctic: evidence for a warm polar ocean, Palaeogeogr. Palaeocl., 128, 227-251, 1997.

Huang, Y.-J., Chen, W.-Y., Jacques, F. M. B., Liu, Y.-S. C., Utescher, T., Su, T., Ferguson, D. K., and Zhou, Z.-K.: Late Pliocene temperatures and their spatial variation at the southeastern border of the Qinghai-Tibet Plateau, J. Asian Earth Sci., 111, 44-53, 2015.

Hutchinson, G. E.: Concluding Remarks, Cold Spring Harbor Symp. Quant. Biol., 22, 415-427, 1957.

Klotz, S.: Neue Methoden der Klimarekonstruktion - angewendet auf quartäre Pollensequenzen der französischen Alpen, Tübinger Mikropaläontologische Mitteilungen, Institut \& Museum für Geologie \& Paläontologie [now: Institute for Geosciences], Eberhard Karls University, Tübingen, 1999.

Köppen, W.: Das geographische System der Klimate, in: Handbuch der Klimatologie, Band 1, Teil C., edited by: Köppen, W. and Geiger, R., Gebr. Borntraeger, Berlin, 1-44, 1936.

Kovach, W. and Spicer, R. A.: Canonical correspondence analysis of leaf physiognomy: a contribution to the development of a new palaeoclimatological tool, Palaeoclimates: Data and Modelling, 2, 125-138, 1995.

Li, S. F., Jacques, F. M. B., Spicer, R. A., Su, T., Spicer, T. E. V., Yang, J., and Zhou, Z.: Artificial neural networks reveal a high-resolution climatic signal in leaf physiognomy, Palaeogeogr. Palaeocl., 442, 1-11, 2016.

Mosbrugger, V. and Utescher, T.: The coexistence approach - a method for quantitative reconstructions of Tertiary terrestrial palaeoclimate data using plant fossils, Palaeogeogr. Palaeocl., 134, 61-86, 1997.

Nix, H. A.: A biogeographic analysis of Australian elapid snakes, in: Atlas of Elapid Snakes of Australia, edited by: Longmore, R., Australian Government Publishing Service, Canberra, 4-15, 1986.

Pearman, P. B., Guisan, A., Broennimann, O., and Randin, C. F.: Niche dynamics in space and time, Trends Ecol. Evol., 23, 149158, 2008a.

Pearman, P. B., Randin, C. F., Broennimann, O., Vittoz, P., van der Knapp, W. O., Engler, R., Le Lay, G., Zimmermann, N. E., and Guisan, A.: Prediction of plant species distributions across six millennia, Ecol. Lett., 11, 357-369, 2008b.

Peterson, A. T., Soberón, J., Pearson, R. G., Anderson, R. P., Martínez-Meyer, E., Nakamura, M., and Araújo, M. B.: Ecological Niches and Geographic Distributions, Princeton University Press, Princeton, 2011.

Potts, A. J., Hedderson, T. A., Franklin, J., and Cowling, R. M.: The Last Glacial Maximum distribution of South African subtropical thicket inferred from community distribution modelling, J. Biogeogr., 40, 310-322, 2013.

Punyasena, S. W.: Estimating Neotropical palaeotemperature and palaeoprecipitation using plant family climatic optima, Palaeogeogr. Palaeocl., 265, 226-237, 2008.
Rödder, D. and Engler, J. O.: Quantitative metrics of overlaps in Grinnellian niches: advances and possible drawbacks, Global Ecol. Biogeogr., 20, 915-927, 2011.

Schroeder, G.-F.: Lehrbuch der Pflanzengeographie, Quelle \& Meyer, Wiesbaden, 1998.

Sexton, J. P., McIntyre, P. J., Angert, A. L., and Rice, K. J.: Evolution and ecology of species range limits, Ann. Rev. Ecol. Evol. Syst., 40, 415-436, 2009.

Spicer, R. A., Valdes, P. J., Spicer, T. E. V., Craggs, H. J., Srivastava, G., Mehrotra, R. C., and Yang, J.: New development is CLAMP: calibration using global gridded meteorological data, Palaeogeogr. Palaeocl., 283, 91-98, 2009.

Thompson, R. S., Anderson, K. H., Pelltier, R. T., Strickland, L. E., Bartlein, P. J., and Shafer, S. L.: Quantitative estimation of climatic parameters from vegetation data in North America by the mutual climatic range technique, Quaternary Sci. Rev., 51, 18-39, 2012.

Tiffney, B. H.: Phylogeography, fossils, and northern hemisphere biogeography: The role of physiological uniformitarianism, Ann. Missouri Bot. Gard., 95, 135-143, 2008.

Tiffney, B. H. and Manchester, S. R.: The use of geological and paleontological evidence in evaluating plant phylogeographic hypotheses in the Northern Hemisphere Tertiary, Int. J. Plant Sci., 162, S3-S17, 2001.

Utescher, T., Bruch, A. A., Erdei, B., François, I., Ivanov, D., Jacques, F. M. B., Kern, A. K., Liu, Y.-S. C., Mosbrugger, V., and Spicer, R. A.: The Coexistence Approach - Theoretical background and practical considerations of using plant fossils for climate quantification, Palaeogeogr. Palaeocl., 410, 58-73, 2014.

Utescher, T., Bondarenko, O. V., and Mosbrugger, V.: The Cenozoic Cooling - continental signals from the Atlantic and Pacific side of Eurasia, Earth Plan. Sci. Lett., 415, 121-133, 2015.

Veloz, S. D., Williams, J. W., Blois, J. L., He, F., Otto-Bliesner, B., and Liu, Z.: No-analog climates and shifting realized niches during the late Quaternary: implications for 21 st-century predictions by species distribution models, Glob. Change Biol., 18, 1698$1713,2011$.

Walter, H.: Vegetation of the Earth in relation to the climate and the eco-physiological conditions, Springer Verlag, New York, Heidelberg, Berlin, 1973.

Walter, H. and Breckle, S.-W.: Ökologie der Erde, Eugen Ulmer Verlag, Stuttgart, 1983-1991.

Yang, J., Spicer, R. A., Spicer, T. E. V., and Li, C.-S.: "CLAMP Online": a new web-based palaeoclimate tool and its application to the terrestrial Paleogene and Neogene of North America, Palaeobiodiversity and Palaeoenvironments, 91, 163-183, 2011.

Yang, J., Spicer, R. A., Spicer, T. E. V., Arens, N. C., Jacques, F. M. B., Su, T., Kennedy, E. M., Herman, A. B., Steart, D. C., Srivastava, G., Mehrotra, R. C., Valdes, P. J., Mehrotra, N. C., Zhou, Z. K., and Lai, J. S.: Leaf form-climate relationships on the global stage: An ensemble of characters, Global Ecol. Biogeogr., 10, 1113-1125, 2015. 